\title{
Structural Analysis of Three-dimensional Human Neural Tissue derived from Induced Pluripotent Stem Cells
}

\section{Patrick Terrence Brooks ${ }^{1 *}$, Mikkel Aabech Rasmussen ${ }^{2}$ and Poul Hyttel ${ }^{1}$}

${ }^{1}$ Department of Veterinary Clinical and Animal Sciences, Faculty of Health and Medical Sciences, University of Copenhagen, Groennegaardsvej 7, Frederiksberg C 1870, Denmark

${ }^{2}$ Bioneer, Kogle Alle 2, Hoersholm 2970, Denmark

\begin{abstract}
Objective: The present study aimed at establishing a method for production of a three-dimensional (3D) human neural tissue derived from induced pluripotent stem cells (iPSCs) and analyzing the outcome by a combination of tissue ultrastructure and expression of neural markers.
\end{abstract}

Methods: A two-step cell culture procedure was implemented by subjecting human iPSCs to a 3D scaffoldbased neural differentiation protocol. First, neural fate-inducing small molecules were used to create a neuroepithelial monolayer. Second, the monolayer was trypsinized into single cells and seeded into a porous polystyrene scaffold and further cultured to produce a 3D neural tissue. The neural tissue was characterized by a combination of immunohistochemistry and transmission electron microscopy (TEM).

Results: iPSCs developed into a 3D neural tissue expressing markers for neural progenitor cells, early neural differentiation and maturation, radial glial cells and cellular proliferation including SOX2, Nestin, $\beta$-III Tubulin, MAP2, Tau, BLBP and Ki67. We found an abundance of rosette structures resembling the morphology of the developing neural tube. These neural tube-like structures (NTLS) were shown to contain areas of neural progenitor cell maintenance and proliferation. The resemblance to the embryonic neural tube was further supported by TEM analyses demonstrating luminal tight junctions and primary cilia. Moreover, the NTLS consisted of radial glial-like cells, radiating from the lumen, and neural progenitor cells presenting elongated nuclei, signaling nucleus transposition seen at interkinetic nuclear migration during early neurogenesis, and mitoses.

Conclusion: Our findings revealed that this relatively simple 3D scaffold-based neural differentiation protocol for human iPSCs was able to recapitulate several key events in early neural development. The organization into NTLS and the presence of mature neural cells in the tissue surrounding these structures showed that this protocol has potential for in vitro studies of neural development and disease modeling.

Keywords: 3D differentiation; Induced pluripotent stem cells; Stem cells; Neural tissue; Neural tube; Immunocytochemistry; Transmission electron microscopy

\section{Introduction}

Since the discovery of induced pluripotent stem cells (iPSCs), first in mice [1] and a year later in man [2], widespread applications of this technology have emerged including creation of patient-specific disease models [3]. Neural cells were some of the first to be derived from human iPSCs. Today, great progress has been achieved in this area in regards to solid protocols for obtaining the different subtypes of cells found in the central nervous system including specific neuronal subtypes and glial cells [4].

Recently, three-dimensional (3D) neural differentiation has received further attention as a way of more precisely mimicking the developmental mechanisms that are active during the early embryology of the central nervous system. Different 3D culture methods have been applied including the forced floating method where gravity or centrifugation is used to produce cellular aggregation into spheroids, the hanging drop method or agitation-based methods [5,6]. Likewise, matrices and scaffolds composed of gels, plastics or other natural/ artificial materials that mimic the spaces created by extracellular matrix and basement membranes in vivo have been applied [6,7]. The scaffolds are often coated with or contain built-in adherence molecules, i.e., laminin, Matrigel or nanofibers that cells will normally cling to in vivo [6]. Moreover, nutrients, waste products and gas distribution become important challenges in $3 \mathrm{D}$ culture methods due to the tissues thickness. To solve this, bioreactor systems can be applied in order to keep the exchange and flow of essential nourishment [7].

When comparing 3D versus traditional two-dimensional (2D) differentiation culture, the cells in 3D systems exhibit higher degree of in vivo-like morphology, behavior, cell-to-cell interactions and organization. For example, cells in 2D culture may take on a squamous morphology, even when their in vivo equivalent is cuboidal, columnar or stellate. This affects the overall tissue organization and cell behavior via signal transduction through intercellular adhesions, which has been shown to alter cellular behaviors i.e., proliferation, differentiation and apoptosis in certain tissues [8]. Cells in 3D culture also grow in multilayers compared to the $2 \mathrm{D}$ monolayers. This adds more in vivolike parameters in regards to both interstitial cell-to-cell interactions via paracrine cues and spatial associations acting though cellular junctions in all three dimensions [8-10].

*Corresponding author: Patrick Terrence Brooks, MD, Department of Veterinary Clinical and Animal Sciences, Faculty of Health and Medical Sciences, University of Copenhagen, Groennegaardsvej 7, Frederiksberg C 1870, Denmark, Tel: +45 23802262; E-mail: ptbrooks@gmail.com

Received March 20, 2016; Accepted April 22, 2016; Published April 29, 2016

Citation: Brooks PT, Rasmussen MA, Hyttel P (2016) Structural Analysis of Threedimensional Human Neural Tissue derived from Induced Pluripotent Stem Cells. J Stem Cell Res Ther 6: 337. doi:10.4172/2157-7633.1000337

Copyright: (c) 2016 Brooks PT, et al. This is an open-access article distributed under the terms of the Creative Commons Attribution License, which permits unrestricted use, distribution, and reproduction in any medium, provided the original author and source are credited. 
A goal when using a $3 \mathrm{D}$ culture method is to be able to mimic cellular behavior seen in vivo and the organization of specific tissues. In stem cell-derived neural tissues this is expressed e.g. in the organization of rosette structures with zones of cell proliferation, differentiation and migration mimicking neural tube development in vivo [11].

In this study we aimed at investigating the structural organization of neural tissue produced from human iPSCs through a 3D neural differentiation protocol. Firstly, iPSCs were differentiated into a neuroepithelial (NE) monolayer using an established neural culture method [12] with the addition of two neural stem cell inducing factors; LDN193189 and SB431542 [13]. Secondly, the neuroepithelial cells were further matured in a porous polystyrene 3D culture system. Our findings showed that human iPSCs were able to differentiate into neural tissue presenting neural tube-like structures (NTLS) that resemble the neural tube during embryogenesis.

\section{Methods and Materials}

\section{Cell culture}

iPSC culture: Human iPSCs previously produced using nonintegrative episomal plasmids [14], were plated on 6-well dishes (140685, Thermo Fischer Scientific, Waltham, MA USA) coated with

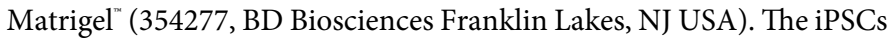
were cultured for 7 days in Essential 8 "' medium (A1517001, Thermo Fischer Scientific) with penicillin/streptomycin (1:1000, P0781, SigmaAldrich, St. Louis, MO USA) at $37^{\circ} \mathrm{C}$ in a hypoxia incubator chamber with $5 \% \mathrm{O}_{2}, 5 \% \mathrm{CO} 2$ in $\mathrm{N} 2$ with media change every 1-2 days until a cell confluence of $70-95 \%$ was reached.

Differentiation to neuroepithelia: The iPSCs were differentiated for 11 days in an established neuroepithelial (NE) medium [12,13] containing equal parts DMEM/F12 (D8437, Sigma-Aldrich) and Neurobasal $^{\mathbb{Q}}$ Medium (21103-049, ThermoFischer Scientific) with addition of N-2 (1:100 dilution, 17502-048, ThermoFischer Scientific) and B-27 (1:50 dilution, 17504-044, ThermoFischer Scientific) as well as penicillin/streptomycin (1:1000) and GlutaMAX (1:1000 dilution, 35050-038, ThermoFischer Scientific). This medium included two small molecules, the TGF- $\beta$ inhibitor SB431542 $(10 \mu \mathrm{M})$ and the BMP inhibitor LDN193189 $(0.2 \mu \mathrm{M})$. Incubator parameters were maintained at $37^{\circ} \mathrm{C}$ and $5 \% \mathrm{O}_{2}, 5 \% \mathrm{CO}_{2}$ in $\mathrm{N} 2$ and medium change was done every 1-2 days. Areas that showed morphological signs of differentiation, i.e., thickening of the monolayer or change in color, were removed manually with a sterile pipette tip. At day 11, the cells were split into single cells using Accutase (A1110501, Thermo Fisher Scientific) and cultured for a further 15 days in neural maintenance medium consisting of NE medium with bFGF (20 ng/ml, CYT557, ProSpec, East Brunswick, NJ USA) and EGF (20 ng/ml, CYT217, ProSpec) without SB431542 and LDN193189 for neural stem cell expansion.

Neural differentiation in a 3D culture system: Three Alvetex ${ }^{\circledR}$ Scaffold 6-well inserts (RE-AVP004-3, 22 mm diameter, Reinnervate, Durham, United Kingdom) were coated with laminin $(10 \mu \mathrm{g} / \mathrm{ml})$ for 4 hours. Dispase $(1 \mathrm{mg} / \mathrm{ml})$ was added to the 6-well dish containing the $\mathrm{NE}$ cells and the dish was incubated for 3 min until the edges of colonies were loosened. The NE layer was then gently broken up into small pieces using a sterile glass pipette and transferred into a $10 \mathrm{ml}$ tube containing DMEM/F12 at $37^{\circ} \mathrm{C}$. The cells were spun down for $2 \mathrm{~min}$ at $1200 \mathrm{rpm}$ and the supernatant was discarded. Resuspension was done in neural maintenance medium [12] with no additional factors added and the cells were plated onto the laminin-coated 3D Alvetex ${ }^{\circledR}$ inserts in a 6-well dish. Each Alvetex ${ }^{\circledR}$ insert contained cells from 2 wells of a 6 well dish. Additional neural maintenance medium was added until the insert was completely covered. The cells were then cultured for an additional 30 days at $37^{\circ} \mathrm{C}$ in a hypoxia incubator chamber with a $5 \%$ $\mathrm{O}_{2}, 5 \% \mathrm{CO}_{2}$ in $\mathrm{N}_{2}$ gas mix in neural maintenance medium with medium change every $1-2$ days.

Immunohistochemistry (IHC): For fixation, $4 \%$ paraformaldehyde/PBS solution was applied for at least 1 hour. Samples were then stored in PBS at $4^{\circ} \mathrm{C}$. The circular Alvetex ${ }^{\circledR}$ porous scaffold containing the tissue was rinsed in PBS and then cut into rectangular strips that were then embedded in $4 \%$ LB Broth with agar (L2897, Sigma-Aldrich). This was done to better control the angle for subsequent microtome sectioning. The blocks for IHC were embedded in Tissue-Tek ${ }^{\circledR}$ (4583, O.C.T ${ }^{\mathrm{T} \times}$ Compound, Sakura, Alphen aan den Rijn, The Netherlands), mounted and cut at $10 \mu \mathrm{m}$ thickness using a cryostat (Leica CM 1950) at a perpendicular angle to the Alvetex ${ }^{\mathbb{B}}$ membrane plane and then stored on coverslips at $-80^{\circ} \mathrm{C}$. The tissue sections were permeabilized using $0.1 \%$ Triton X-100 (108643, Merck Millipore, Billerica, MA USA) in PBS for 15 minutes and blocked using 5\% Normal Donkey Serum (S30, Merck Millipore) and 1\% Bovine Serum Albumin (A7906, Sigma-Aldrich) in PBS for 1 hour. The primary antibodies (Table 1 ) were diluted in $0.25 \%$ BSA in $0.1 \%$ Triton $\mathrm{X}-100$ in PBS and the samples were incubated at $4^{\circ} \mathrm{C}$ overnight. The following day the samples were washes for 3 rounds of 5 minutes in PBS. The secondary antibodies, Alexa Fluor ${ }^{\circledR} 488$ donkey anti-mouse (A-21202, Thermo Fischer Scientific) and Alexa Fluor ${ }^{\circledR} 594$ donkey anti-rabbit (A-21206, Thermo Fischer Scientific) were diluted in $0.25 \%$ BSA in $0.1 \%$ Triton X-100 in PBS and the samples were incubated for 1 hour at room temperature. After three 5-minute PBS washings, the samples were stained with $0.1 \mu \mathrm{L} / \mathrm{ml}$ Hoechst trihydrochloride (H3570, Thermo Fischer Scientific) for 3 minutes. Finally they were washed for 5 minutes in PBS and were mounted in fluorescent mounting medium (S3023, DAKO, Glostrup, Denmark). Imaging was done using an EVOS FL Imaging System. Negative controls for unspecific staining of the secondary antibodies was performed by omitting the primary antibodies (Table 1, Supplementary Figure 2). In addition, negative control for the primary antibody for Tau was performed by staining with isotype antibody.

Transmission electron microscopy (TEM): Alvetex $^{\circledR}$ tissue fixation for TEM was done in a $3 \%$ glutaraldehyde $/ 0.1 \mathrm{M}$ sodium phosphate buffer for 1 hour and the samples (cut into $2 \times 7 \mathrm{~mm}$ strips) were embedded in 4\% LB Broth with agar (L2897, Sigma-Aldrich). The samples were then washed in $0.1 \mathrm{M}$ sodium phosphate buffer, post-fixed in $1 \% \mathrm{OsO}_{4}$ in $0.1 \mathrm{M}$ sodium phosphate buffer, dehydrated in graded

\begin{tabular}{|c|c|c|c|}
\hline Antibody and species & $\begin{array}{c}\text { Product number/ } \\
\text { Company }\end{array}$ & Dilution & Negative Control \\
\hline $\begin{array}{c}\text { SOX2 - monoclonal } \\
\text { mouse }\end{array}$ & Mab2018/ R\&D Systems & $1: 100$ & No primary Ab \\
\hline $\begin{array}{c}\text { Nestin - monoclonal } \\
\text { mouse }\end{array}$ & Mab5326/ Milipore & $1: 400$ & No primary Ab \\
\hline $\begin{array}{c}\text { Ki67 - monoclonal } \\
\text { mouse }\end{array}$ & M7240, DAKO & $1: 200$ & No primary Ab \\
\hline $\begin{array}{c}\text { Ki67 - monoclonal rabbit } \\
\text { R-III Tubulin - monoclonal } \\
\text { mouse }\end{array}$ & $\begin{array}{c}\text { Fischer Scientific } \\
\text { T8660/ Sigma-Aldrich }\end{array}$ & $1: 200$ & No primary Ab \\
\hline Tau - polyclonal rabbit & A0024/ DAKO & $1: 1000$ & Ig fraction X0936 \\
\hline $\begin{array}{c}\text { MAP2 - monoclonal } \\
\text { mouse }\end{array}$ & M1406/ Sigma-Aldrich & $1: 200$ & No primary Ab \\
\hline $\begin{array}{c}\text { BLBP - monoclonal } \\
\text { mouse }\end{array}$ & ABN14/Millipore & $1: 2000$ & No primary Ab \\
\hline
\end{tabular}

Table 1: Overview of primary antibodies used in immunohistochemistry of 3D neural tissue. 
Citation: Brooks PT, Rasmussen MA, Hyttel P (2016) Structural Analysis of Three-dimensional Human Neural Tissue derived from Induced Pluripotent Stem Cells. J Stem Cell Res Ther 6: 337. doi:10.4172/2157-7633.1000337

Page 3 of 7

series of ethanol and embedded in Epon (812 resin, Aldermaston, United Kingdom) using propylene oxide as an intermediate. Curing was done for 48 hours at $60^{\circ} \mathrm{C}$. Semi thin sections of $1 \mu \mathrm{m}$ were cut using an ultramicrotome (Leica Ultracut, Leica Microsystems, Wetzlar, Germany) with a glass knife (LKB Bromma 7800, Leica Microsystems) and stained with $1 \%$ toluidine blue (1159300025, Merck Millipore). Ultrathin sections of $50-70 \mathrm{~nm}$ were cut using a diamond knife (Jumdi $2 \mathrm{~mm}$ ) on an ultramicrotome (Leica Ultracut). The sections were collected on copper grids coated with a parlodion/amyl acetate film and contrasted with $2 \%$ uranyl acetate (21447, Polysciences Inc., Warrington, PA USA) and $1 \%$ lead citrate. Imaging of the samples was done using a Morada camera mounted on a Phillips CM100 transmission electron microscope.

\section{Results}

In this study, iPSCs were differentiated into a monolayer of neuroepithelium by use of two small molecules that inhibit BMP and TGF- $\beta$. Further differentiation in scaffold produced 3D neural tissue. The tissue grew above, inside and below the scaffold. The perpendicular height of the tissue above the scaffold ranged from about 200 to 600 $\mu \mathrm{m}$ at the center of the sample. The amount of tissue below the scaffold varied and was much scarcer than above growing up to $200 \mu \mathrm{m}$ below the scaffold (Figure 1). Abundant lacunae were observed throughout the tissue and neural tube like structures (NTLS) were observed (Figure 1). These NTLS were exclusively found in the tissue outside the scaffold and never inside the scaffold pores.

\section{Immunohistochemistry (IHC) of iPSC-derived neural tissue}

Neural tube-like structures displayed markers of early neurogenesis: The tissue displayed expression of neural and proliferative markers on spatially distinct localizations in relation to the NTLS. IHC staining for SOX2 was mainly observed in the nuclei of the inner 3-6 cell layers surrounding the lumen of the NTLS (Figures 1A-1C), whereas staining for Ki67 was observed in the nuclei of the inner layers of these cells towards the NTLS lumen (Figures 1D-1F) indicating proliferation of neural stem cells at this location. A double staining with SOX2 and Ki67 validated that the NTLS were indeed centers of neural stem cell proliferation (Supplementary Figure 1). IHC staining for Nestin was observed in the cytoplasm of cells forming the NTLS as well as in the surrounding tissue outside of the NTLS (Figures 1G-1I). To assess if radial glial cells were also present in the tissue, staining with brain lipid binding protein (BLBP) was performed. Elongated cells radiating from the NTLS did indeed stain positive for BLBP (Figures 1J-1L). BLBP was mainly concentrated in a pattern radiating from the NTLS lumen, but also stained scattered cells in other areas of the tissue.
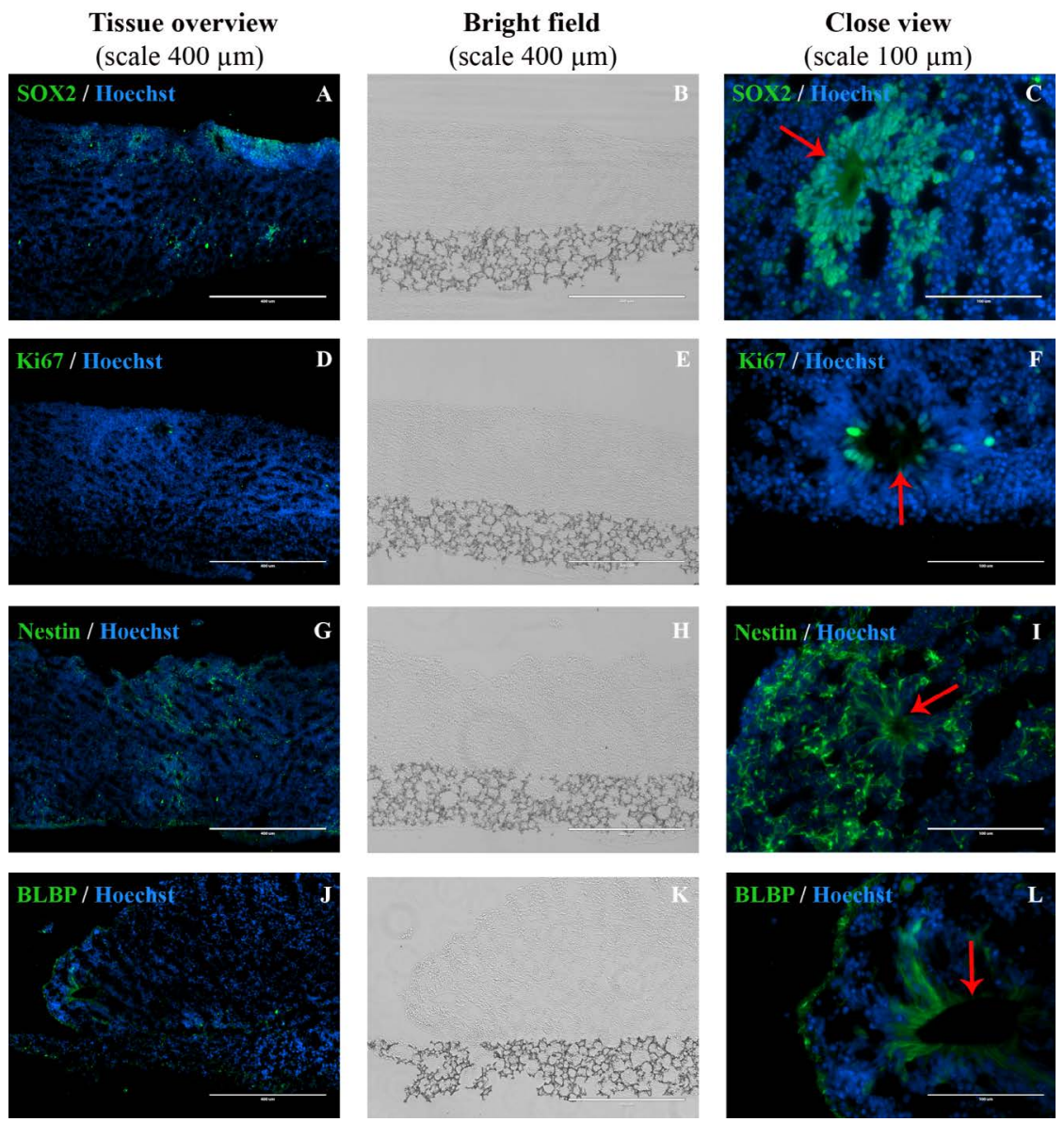

Primary antibodies (green) were SOX2 (A, C), Ki67 (D, F), Nestin (G, I), Nuclei were stained with Hoechst (blue). The first column is a "Tissue overview" (scale 400 $\mu \mathrm{m}$ ), the second column is a "Bright field" showing the position of the tissue on the scaffold. The third column shows a close up view of the tissue, where a red arrow marks neural tube-like structures (NTLS).

Figure 1: Immunohistochemistry $(\mathrm{IHC})$ staining of human induced pluripotent stem cells differentiated in a scaffold into 3D neural tissue. 
Tissue outside of neural tube-like structures stained for more mature markers: Staining for the immature neural marker $\beta$-III Tubulin was mainly observed in the cytoplasm of cells in the surrounding tissue outside of the NTLS (Figures $2 \mathrm{~A}-2 \mathrm{C}$ ), but was also observed in a few NTLS. Staining for the more mature neural marker Tau was only observed in the cytoplasm of cells in the surrounding tissue outside the NTLS (Figures 2D-2F). The same was true for MAP2, which was especially prominent on the bottom side of the scaffold membrane (Figures 2G-2I). Some variation with respect to the degree of staining was noted between different NTLS (data not shown). All negative control stainings were free of labeling (Supplementary Figure 2).

\section{TEM of iPSC-derived neural tissue}

NTLS show ultrastructural characteristics resembling embryonic neural tube: The NTLS presented a well-defined lumen delineated by an epithelium in which many mitoses were noted (Figure 3A), some with visible centrioles (Figure 3C). The epithelial cells lining the lumen displayed prominent tight junctions (Figures $3 \mathrm{~B}, 3 \mathrm{D}$ and $3 \mathrm{~F}-3 \mathrm{I})$ defining an apical cell compartment presenting basal bodies (Figures 3D, 3F and $3 \mathrm{H}$ ) and primary cilia (Figures 3I and $3 \mathrm{H}$ ) with $9+0$ axonemal microtubule conformation, as well as microvilli (Figure 3E). At low magnifications, the NTLS displayed a radiating cellular arrangement (Figures 4A-4D). The neuroepithelium of the NTLS was pseudostratified and consisted of neural progenitor cells and radiating neural glial-like cells. The neural progenitor cells presented either round or elongated nuclei or mitotic configurations. The elongated nuclei signaled nucleus transposition seen at interkinetic nuclear migration during early neurogenesis (Figures $4 \mathrm{~A}$ and $4 \mathrm{~B}$ ). The neural progenitor cells undergoing mitosis were all located within 10 $\mu \mathrm{m}$ of the NTLS lumen, while round and elongated interphase nuclei were located further than $10 \mu \mathrm{m}$ from the lumen indicating that mitoses occurred juxtaposed to the lumen (Figures 3A, 4A and 4B). At a distance of at least $50 \mu \mathrm{m}$ from the NTLS lumen, round nuclei of cells that resembled radial glia were noted (Figures 4C and 4D). These cells presented an immensely elongated cytoplasm extending from the NTLS lumen towards the external delineation of the NTLS (Figures 4C and 4D). Neural progenitor cells were closely associated with these elongated stretches of cytoplasm giving the impression of a directed movement along the elongated radiating cells (Figures $4 \mathrm{C}$ and 4D). The tissue further away from the NTLS showed neuron bodies displaying nuclei with adjacent Golgi complexes as well as smooth and rough endoplasmic reticulum. These cells were surrounded by a dense mesh of neurite-like cellular extensions cut at varying orientations containing an abundance of microtubules and mitochondria (Figures $4 \mathrm{E}$ and $4 \mathrm{~F}$ ). Empty lacunae were interspersed in this tissue.

\section{Discussion}

The results showed that human iPSCs could be differentiated into tissue that under relatively minimalistic $3 \mathrm{D}$ culture parameters stained positively for several markers that characterize early embryonic neurogenesis. Moreover, the tissue presented NTLS, which, with respect to spatial organization and ultrastructural features, showed a remarkable resemblance to that of the embryonic neural tube where the lumen is lined by a neuroepithelium consisting of the end feet of neural progenitor cells and radial glial cells. In the neural tube, the nuclei of the neural progenitor cells reside in the ventricular zone where they undergo interkinetic nuclear migration with mitosis occurring in the luminal compartment of the cells [15-17]. Accordingly, we found that the NTLS expressed SOX2, Ki67 Nestin, and, in a few examples,
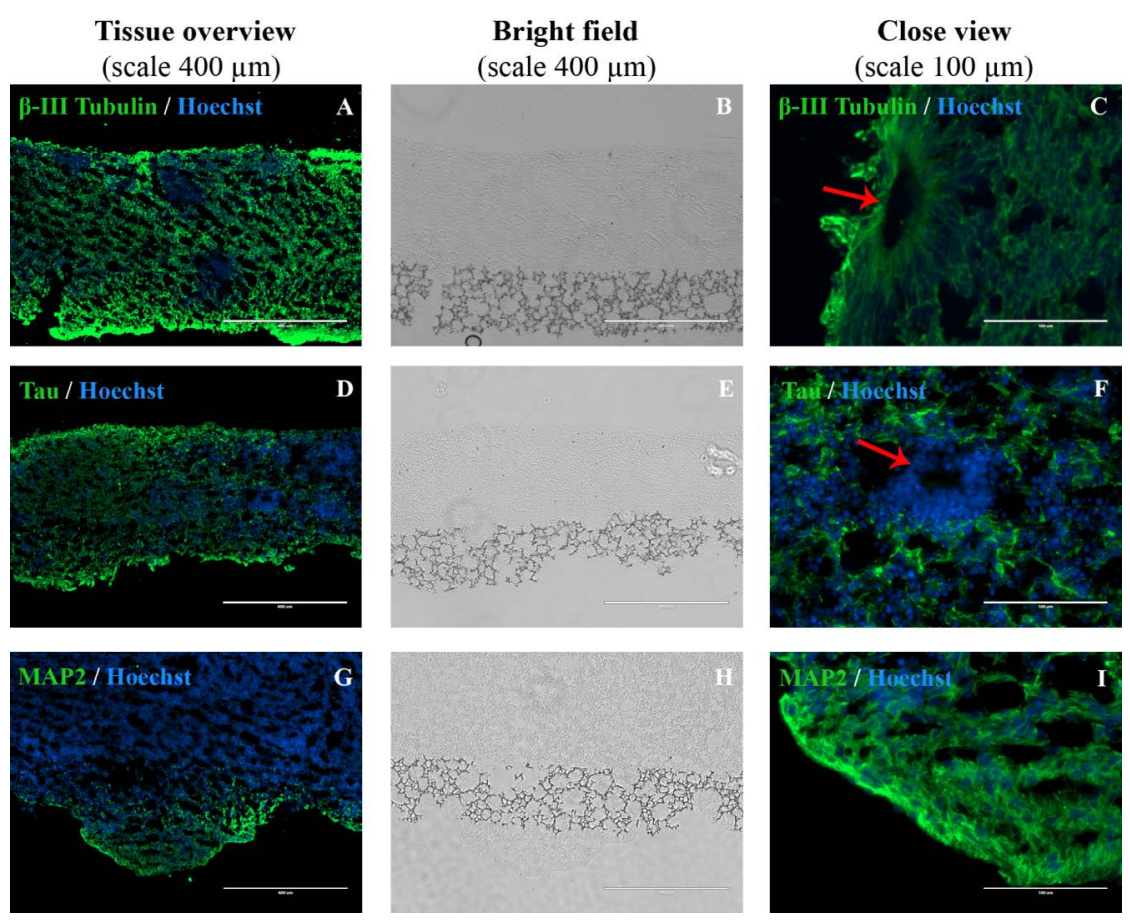

Primary antibodies (green) stained for $\beta$-Tubulin III (A, C), Tau (D, F) and MAP2 (G, I). Nuclei were stained with Hoechst (blue). The first column is a "Tissue overview" (scale $400 \mu \mathrm{m}$ ), the second column is a "Bright field" showing the position of the tissue on the scaffold. The third column shows a close up view of the tissue, where a red arrow marks neural tube-like structures (NTLS).

Figure 2: Immunohistochemistry (IHC) staining of human induced pluripotent stem cells differentiated in a scaffold into 3D neural tissue. 

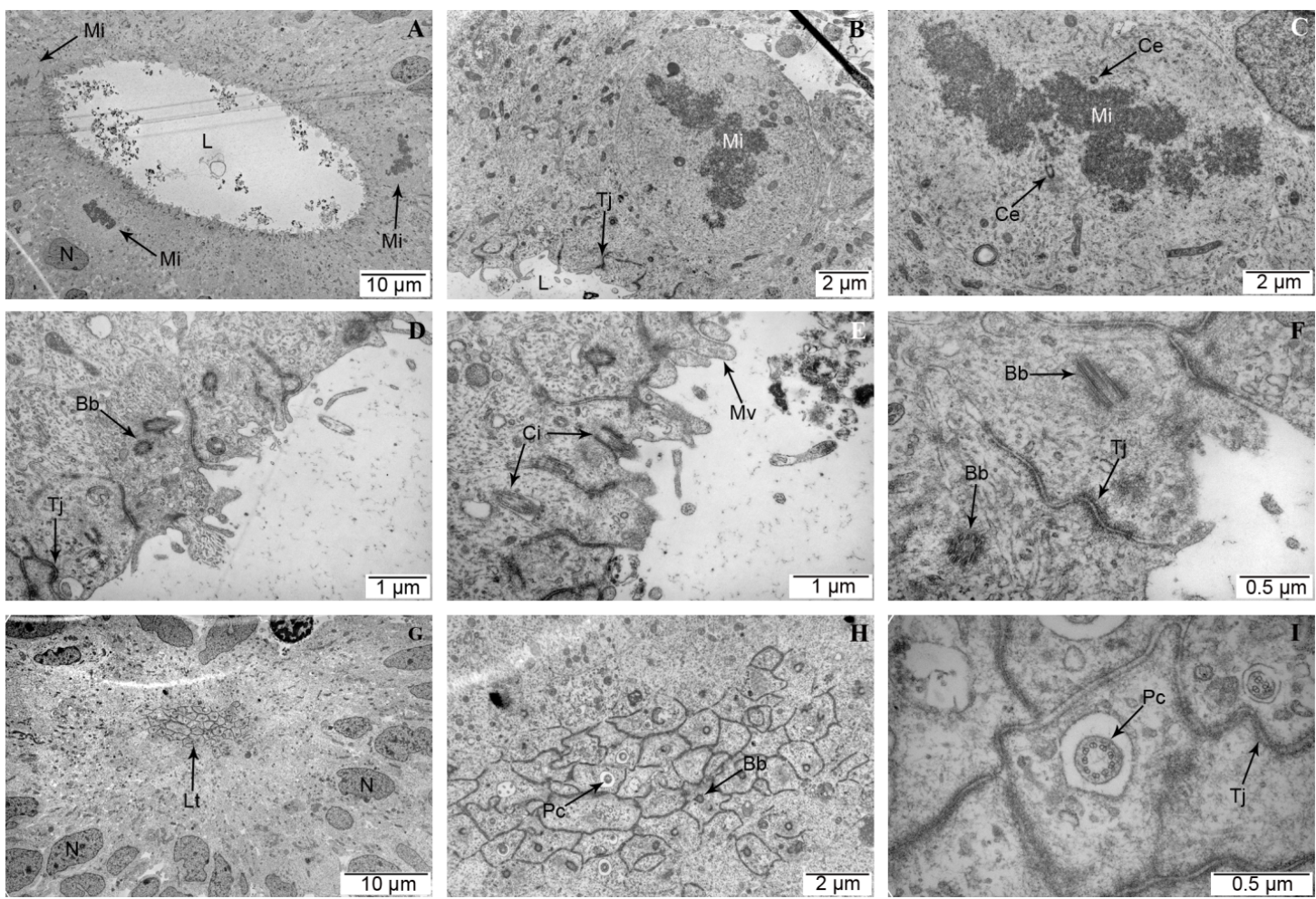

Images of ultrastructural components resembling the developing neural tube. A (scale bar $10 \mu m$ ): overview of the NTLS lumen (L) with periluminar mitoses (Mi). B (scale bar $2 \mu \mathrm{m}$ ): Close view of mitosis (Mi) next to lumen (L) with visible tight junctions (Tj) at apical cell lining. C (scale bar $2 \mu \mathrm{m})$ : Periluminar mitosis (Mi) with visible centrioles $(\mathrm{Ce})$. D (scale bar $1 \mu \mathrm{m})$ : Luminal epithelial lining with basal bodies $(\mathrm{Bb})$ and tight junctions (Tj). E (scale bar $1 \mu \mathrm{m})$ : Luminal epithelial lining with cilia $(\mathrm{Ci})$ and microvilli (Mv). F (scale bar $0.5 \mu \mathrm{m}$ ): Luminal epithelial lining with basal bodies (Bb) and tight junctions (Tj). $\mathrm{G}(\mathrm{scale}$ bar $10 \mu \mathrm{m})$ : Luminal tangential cut (Lt) with surrounding nuclei $(\mathrm{N})$. $\mathrm{H}$ (scale bar $2 \mu \mathrm{m})$ : Closer view of luminal tangential cut showing presence of primary cilia (Pc) and basal bodies (Bb). I (scale bar $0.5 \mu \mathrm{m}$ ): Close up view of luminal tangential cut showing primary cilia $(\mathrm{Pc})$ and tight junctions $(\mathrm{Tj})$.

Figure 3: Transmission electron micrographs of neural tube-like structure (NTLS) produced from human induced pluripotent stem cells using a 3D scaffold based culture method.

$\beta$-III Tubulin. They also displayed neuroepithelial and radial glia-like cell morphologies mimicking in vivo development. The cells outside the NTLS stained positive for $\beta$-III Tubulin, Tau and MAP2, which indicated more mature cell types residing further away from the NTLS. The NTLS resembled previously reported neural rosette structures seen in monolayer culture [12] as well as self-organizing neural aggregates, polarized cortical tissue and other central nervous system structures [18-21].

The applied neural immunohistochemical markers identified the presence of distinct spatial functional zones in relation to the NTLS. SOX2 was found in the inner cell layers towards the NTLS lumen identifying neural progenitor cells. Ki67 was restricted to the innermost cell layers towards the lumen identifying this zone as being a site of active neural progenitor cell proliferation. This phenomenon was in accordance with our TEM results showing that the NTLS had a pseudostratified appearance with multiple metaphases in the inner cell layer with the presence of centrioles resembling apical neural progenitor cells seen in vivo [22,23]. Moreover, some of the neural progenitor cells displayed elongated nuclei radiating from the NTLS indicating interkinetic nuclear migration typical for mitoses during early neurogenesis $[15,17]$. The NTLS lumen displayed ultrastructural resemblance to that of the in vivo neural tube [24] and was sealed by apical tight junctions, and the apical cell compartment lining the lumen presented basal bodies, primary cilia and microvilli also characteristic for the neural tube [25]. Nestin, another neural progenitor cell marker, was also present in the inner layers of the NTLS as well as in areas a bit further away from the NTLS. It was also seen in areas in the surrounding tissue where NTLS were not clearly present.

At a distance of about $50 \mu \mathrm{m}$ from the NTLS lumen in our TEM images, we observed small round nuclei of cells with an elongated cytoplasm radiating from the lumen. These morphological characteristics and this positioning indicated that these could indeed be radial glial cells. In close proximity to the cell soma of these radial glial-like cells, potential neural progenitor cells were found indicating movements of these cells along the extended radial-glial-like cell cytoplasm. Radial glial cells are known to present apical-to-basal polarity and to organize the neurogenic zone with their apical end feet positioned at the neural tube lumen and their extended cytoplasm radiating from this position $[21,22,26]$. The primary cilia with a $9+0$ microtubular conformation, which were observed protruding into the lumen of the NTLS, could potentially belong to these radial glial-like cells and be linked to signal transduction of $\mathrm{SHH}$, as documented in the developing neural tube of mammals [27]. Finally, by application of staining for BLBP, which has previously been used for staining of radial glial cells in human fetal CNS tissue [28] we achieved a clear labeling radiating from the NTLS. This result supports the notion the presence of radial glia around the NTLS that may have serve to guide neural progenitors from the proliferative inner layers of the NTLS into the surrounding tissue. 
Citation: Brooks PT, Rasmussen MA, Hyttel P (2016) Structural Analysis of Three-dimensional Human Neural Tissue derived from Induced Pluripotent Stem Cells. J Stem Cell Res Ther 6: 337. doi:10.4172/2157-7633.1000337

Page 6 of 7
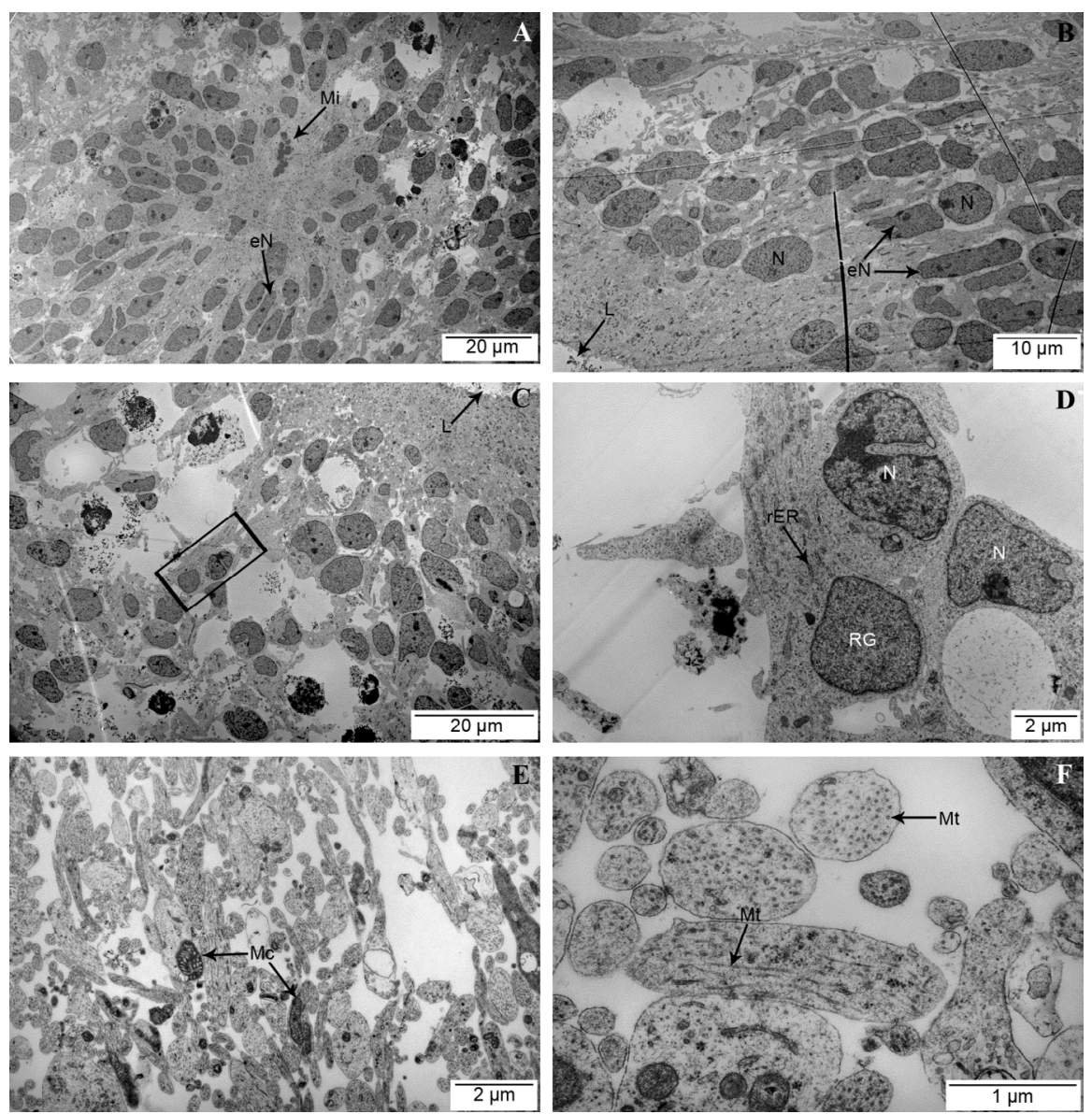

A (scale bar $20 \mu \mathrm{m}$ ): NTLS overview with the notion of close by lumen showing mitosis (Mi) and elongated nuclei (eN). B (scale bar $10 \mu \mathrm{m})$ : Periluminar NTLS view with visible lumen (L), elongated nuclei $(\mathrm{eN})$ and round nuclei $(\mathrm{N})$. C (scale bar $20 \mu \mathrm{m}$ ): Periluminar NTLS view with visible lumen (L) and radial glia-like cell (black box) with elongated cytoplasm radiating towards lumen. D (scale bar $2 \mu \mathrm{m}$ ): Close up view of radial glia-like cell (RG) with visible rough endoplasmic reticulum ( $r E R$ ), seen in figure $\mathrm{C}$, with another cell positioned close to its nucleus $(\mathrm{N})$. $E$ (scale bar $2 \mu \mathrm{m}$ ): Mesh of axon-like cellular extensions seen in the surrounding tissue. Here cut at varying orientation with mitochondria (Mc) present. F (scale bar $1 \mu \mathrm{m}$ ): Close view of axon-like cellular extensions with microtubules (Mt) seen in different orientations.

Figure 4: Transmission electron micrographs of neural tube-like structure (NTLS) as well as surrounding tissue produced from human induced pluripotent stem cells using a monolayer-to-3D scaffold based culture method.

The tissue surrounding the NTLS expressed the neural markers $\beta$-III Tubulin, Tau and MAP2. $\beta$-III Tubulin was, however, also present in some NTLS. The presence of these neural markers, combined with the absence of SOX2, indicates that the tissue outside the NTLS is further differentiated neural tissue. Accordingly, our ultrastructure observations in these areas revealed neuron bodies with Golgi complexes as well as smooth and rough endoplasmic reticulum surrounded by a dense mesh of neurites containing abundant microtubules and mitochondria. In the tissue surrounding the NTLS, lacunae may provide routes for better nutrient and gas diffusion.

The presented mimicking of events representing early neurogenesis in the neural tube was obtained by the use of reasonably simple differentiation culture mediums and an easy-to-use 3D culture system. Whether or not the scaffold contributed to the growth of the tissue, it at least supplied a manageable structure on which to seed the neuroepithelial cells. Hence, it represents an easy approachable method for production of 3D neural tissue for e.g. modeling of neural development and disease mechanisms. We aim at testing the usefulness of the system for modeling of Alzheimer's disease and frontotemporal dementia using iPSCs derived from patients with familial forms of these conditions [29-33].
In addition to this, it will be relevant to perform sequential characterization at different time intervals during the $3 \mathrm{D}$ culture differentiation to study how NTLS formation and development proceeds over time, and if possible, see how much these structures resemble the mechanistic functions of the embryonic neural tube. Furthermore, the system also offers itself for studying differentiation cues by e.g. introduction of gradients of growth factors and other signaling molecules.

In conclusion, a simple 3D scaffold-based neural differentiation protocol for human iPSCs recapitulated several key events in early neural development. The organization into NTLS and the presence of further differentiated cells in the tissue surrounding these structures showed potentials of the model for future studies of neural development and disease modeling.

\section{Acknowledgements}

We thank the following agencies for financial support: the European Union 7th Framework Program (PIAP-GA-2012-324451-STEMMAD), Innovation Fund Denmark "Brainstem" (4108-00008B) and the UCPH Excellence Programme for Interdisciplinary Research (Consortium for Designer Organisms). The Alvetex scaffold were graciously donated by In vitro A/S, Fredensborg, Denmark. The work done would not have had the same quality without the expert technical 
Citation: Brooks PT, Rasmussen MA, Hyttel P (2016) Structural Analysis of Three-dimensional Human Neural Tissue derived from Induced Pluripotent Stem Cells. J Stem Cell Res Ther 6: 337. doi:10.4172/2157-7633.1000337

support from Hanne Mølbak Holm and Tina Christoffersen to whom we express our gratitude. We also wish to thank Professor Kjeld Møllgård of the University of Copenhagen for his guidance in the characterization process. Finally, thanks and appreciation also goes to the Group for Stem Cells and Embryology, Department of Veterinary Clinical and Animal Sciences, the Faculty of Health Sciences, University of Copenhagen

\section{References}

1. Takahashi K, Yamanaka S (2006) Induction of pluripotent stem cells from mouse embryonic and adult fibroblast cultures by defined factors. Cell 126: 663-676. [PubMed]

2. Takahashi K, Tanabe K, Ohnuki M, Narita M, Ichisaka T, et al. (2007) Induction of pluripotent stem cells from adult human fibroblasts by defined factors. Cell 131: 861-872. [PubMed]

3. Sterneckert JL, Reinhardt P, Schöler HR (2014) Investigating human disease using stem cell models. Nat Rev Genet 15: 625-639. [PubMed]

4. Tabar V, Studer L (2014) Pluripotent stem cells in regenerative medicine: challenges and recent progress. Nat Rev Genet 15: 82-92. [PubMed]

5. Breslin S, O'Driscoll L (2013) Three-dimensional cell culture: the missing link in drug discovery. Drug Discov Today 18: 240-249. [PubMed]

6. Greiner JFW, Kaltschmidt B, Kaltschmidt C, Widera D (2013) Going 3D - Cell Culture Approaches for Stem Cell Research and Therapy. Current Tissue Engineering 2: 8-19.

7. Haycock JW (2011) 3D Cell Culture - Methods and Protocols. Methods in Molecular Biology Springer Protocols, Humana Press, New York.

8. Baker BM, Chen CS (2012) Deconstructing the third dimension: how 3D culture microenvironments alter cellular cues. J Cell Sci 125: 3015-3024. [PubMed]

9. Page H, Flood P, Reynaud EG (2013) Three-dimensional Tissue Cultures: Current Trends and Beyond. Cell Tissue Res 352: 123-131. [PubMed]

10. Hakkinen KM, Harunaga JS, Doyle AD, Yamada KM (2011) Direct Comparisons of the Morphology, Migration, Cell Adhesions, and Actin Cytoskeleton of Fibroblasts in Four Different Three-Dimensional Extracellular Matrices. Tissue Eng Part A 17: 713-724. [PubMed]

11. Martinez Y, Dubois-Dauphin M, Krause KH (2012) Generation and Applications of Human Pluripotent Stem Cells Induced into Neural Lineages and Neura Tissues. Frontiers in Physiology 3: 1-9. [PubMed]

12. Shi Y, Kirwan P, Livesey FJ (2012) Directed differentiation of human pluripoten stem cells to cerebral cortex neurons and neural networks. Nat Protoc 7: 18361846. [PubMed]

13. Chambers SM, Qi Y, Mica Y, Lee G, Zhang XJ, et al. (2012) Combined smallmolecule inhibition accelerates developmental timing and converts human pluripotent stem cells into nociceptors. Nat Biotechnol 30: 715-720. [PubMed]

14. Rasmussen MA, Holst B, Tümer Z, Johnsen MG, Zhou S, et al. (2014) Transient p53 Suppression Increases Reprogramming of Human Fibroblasts without Affecting Apoptosis and DNA Damage. Stem Cell Reports 3: 404-413. [PubMed]

15. Götz M, Huttner WB (2005) The Cell Biology of neurogenesis. Nat Rev Mol Cell Biol 6: 777-788. [PubMed]

16. Sild M, Ruthazer ES (2011) Radial Glia: Progenitor, Pathway and Partner Neuroscientist 17: 288-302. [PubMed]
17. Fietz SA, Huttner WB (2011) Cortical progenitor expansion, self-renewal and neurogenesis - a polarized perspective. Curr Opin Neurobiol 21: 23-35. [PubMed]

18. Eiraku M, Watanabe K, Matsuo-Takasaki M, Kawada M, Yonemura S, et al. (2008) Self-Organized Formation of Polarized Cortical Tissues from ESCs and Its Active Manipulation by Extrinsic Signals. Cell Stem Cell 3: 519-532. [PubMed]

19. Eiraku M, Sasai Y (2011) Mouse embryonic stem cell culture for generation of three-dimensional retinal and cortical tissues. Nat Protoc 7: 69-79. [PubMed]

20. Eiraku M, Sasai Y (2012) Self-formation of layered neural structures in threedimensional culture of ES cells. Curr Opin Neurobiol 22: 768-777. [PubMed]

21. Muguruma K, Nishiyama A, Kawakami H, Hashimoto K, Sasai Y (2015) SelfOrganization of Polarized Cerebellar Tissue in 3D Culture of Human Pluripotent Stem Cells. Cell Rep 10: 1-14. [PubMed]

22. Farkas LM, Huttner WB (2008) The cell biology of neural stem and progenitor cells and its significance for their proliferation versus differentiation during mammalian brain development. Curr Opin Cell Biol 20: 707-715. [PubMed]

23. Poul MH (2010) Essentials of Domestic Animal Embryology. Saunders, Edinburgh, New York.

24. Geelen JA, Langman J (1979) Ultrastructural Observations on Closure of the Neural Tube in the Mouse. Anat Embryol (Berl) 156: 73-88. [PubMed]

25. Bancroft M, Bellairs R (1975) Differentiation of the Neural Plate and Neura Tube in the Young Chick Embryo. Anat Embryol (Berl) 147: 309-335. [PubMed]

26. Madarász E (2013) Neural Stem cells - New Perspectives. InTechOpen. Croatia.

27. Bay SN, Caspary T (2012) What are those cilia doing in the neural tube? Cilia 1: 19. [PubMed]

28. Brøchner CB, Holst CB, Møllgård K (2015) Outer brain barriers in rat and human development. Front Neurosci 9: 75. [PubMed]

29. Li T, Pires C, Nielsen TN, Waldemar G, Hjermind LE, et al. (2016) Generation of induced pluripotent stem cells (iPSCs) from an Alzheimer's disease patient carrying a M146I mutation in PSEN1. Stem Cell Res 16: 334-337.

30. Li T, Pires C, Nielsen TN, Waldemar G, Hjermind LE, et al. (2016) Generation of induced pluripotent stem cells (iPSCs) from an Alzheimer's disease patient carrying an A79V mutation in PSEN1. Stem Cell Res 16: 229-232.

31. Rasmussen MA, Hjermind LE, Hasholt LF, Waldemar G, Nielsen JE, et al. (2015) Induced pluripotent stem cells (iPSCs) derived from a patient with frontotemporal dementia caused by a P301L mutation in microtubuleassociated protein tau (MAPT). Stem Cell Res 16: 70-74.

32. Rasmussen MA, Hjermind LE, Hasholt LF, Waldemar G, Nielsen JE, et al. (2015) Induced pluripotent stem cells (iPSCs) derived from a patient with frontotemporal dementia caused by a R406W mutation in microtubuleassociated protein tau (MAPT). Stem Cell Res 16: 75-78

33. Rasmussen MA, Hjermind LE, Hasholt LF, Waldemar G, Nielsen JE, et al. (2015) Induced pluripotent stem cells (iPSCs) derived from a pre-symptomatic carrier of a R406W mutation in microtubule-associated protein tau (MAPT) causing frontotemporal dementia. Stem Cell Res 16: 105-109. 